\title{
How Self-Rated is Self-Rated Health? Exploring the Role of Individual and Institutional Factors in Reporting Heterogeneity in Russia
}

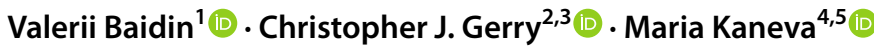

Accepted: 26 December 2020 / Published online: 25 January 2021

(c) The Author(s) 2021

\begin{abstract}
In recent years the literature exploring the state dependent nature of individual self-rated health has grown rapidly. We contribute to this 'reporting heterogeneity' research field in two main ways. First, we are among the few studies to examine the determinants of reporting heterogeneity in self-rated health in the Russian context. Second, echoing the social determinants of health literature, we augment the standard battery of individual level socioeconomic and demographic characteristics with aggregated macro level variables serving as proxies for local environmental and social conditions. We are not aware of other heterogeneity studies that have incorporated this approach. Estimating a generalized ordered probit model we resolve the identification problem through the inclusion of an objective disease index. In terms of reporting heterogeneity, we find that response behaviour is systematically influenced by individual characteristics but also by aggregate regional socioeconomic characteristics. In particular, the finding that an individual's relative standing in their local economy can condition their response to subjective health questionnaires is important and merits further examination. We argue that both a relative income mechanism and a mechanism that links the cognitive process of choice with the sense of optimism that individuals have for their institutional environment are plausible explanations for the observed aggregate level effects.
\end{abstract}

Keywords Reporting heterogeneity · Self-rated health $\cdot$ Self-assessed health $\cdot$ Subjective health $\cdot$ Cut point shifts $\cdot$ Index shifts $\cdot$ Russia $\cdot$ RLMS-HSE

\section{Introduction}

Interest in understanding and explaining the nature and causes of comparative health outcomes across and within countries and by socioeconomic and demographic subgroup has expanded dramatically during the last three decades. The rapid increase in the use of individual and household population surveys for collecting socioeconomic, demographic and health data has given rise to self-rated health becoming one of the

Christopher J. Gerry

christopher.gerry@sant.ox.ac.uk

Extended author information available on the last page of the article 
most frequently utilised health measurements in social science research. Its rise is not only due to the financial and logistical practicalities associated with the collection of biomarkers or other clinically oriented health measures but also reflects its predictive association with mortality (Idler and Benyamini 1997; De Salvo et al. 2005; Doiron et al. 2015) and its potential comprehensiveness as a measure of health (Jylha 2009). In 1996, the World Health Organization (WHO) recommended the employment of selfrated health as a principal tool for monitoring the health and quality of life of the population (Health interview 1996) and self-rated measures are now widely used in Health Technology Assessments to inform the allocation of health resources. In this context it is therefore important that the properties of self-rated health data-both in general and for particular populations-are well understood.

The typical population survey question on self-rated health (hereafter SRH) asks respondents: "In general, how would you rate your health?- - very good, good, average, bad or very bad". Results from these surveys have been used to examine population health patterns in relation to income (Frijters et al. 2005), socioeconomic status (Contoyannis et al. 2004), social capital (O’Doherty et al. 2017), retirement (Eibach 2015) and the life-course (Bauldry et al. 2012). It is assumed that the underlying components that inform SRH somehow proxy 'true' health by reflecting the presence (or absence) of, physical and mental illnesses, disabilities or constraints in physical functioning, pain and discomfort, and other medical conditions. Yet, in reality, responses to SRH questions are a product of subjective, cognitive-emotional processes that are specific to prevailing social, economic and cultural settings. That is, in self-rating health in this ordinal manner, an individual's response is informed by myriad factors, other than their true health, including education, environment, gender relations, social networks, labour market status, the presence or absence of longterm chronic conditions and culture. If this is so, then SRH is as much a health-related social construct (Kaplan et al. 1976) as it is a measure of 'true' underlying health. This is not to deny that SRH is linked in important ways to underlying physiological and psychological states but simply to contend that an individual's comprehension of these states is itself a function of socioeconomic and demographic characteristics, health behaviours and expectations, and national, neighbourhood and peer comparisons.

It is because of these internal evaluative processes and the context specific frames of reference within which they occur that SRH necessarily incorporates an unknown element of subjectivity which, if non-random and variable across distinct sub-groups, could give rise to systematic biases when comparing SRH across time, place and population subgroup. This phenomenon, of systematic differences in SRH, according to population markers (e.g. gender, religion, age, region, education level) is known as "reporting heterogeneity" (Shmueli 2003; Lindeboom and van Doorslaer 2004). It captures the idea that, for a given true underlying but unobserved health state, individuals self-rate their health in ways that are systematically conditioned by observed or unobserved characteristics. If this is the case, then two individuals-with the same underlying true health states-may self-rate their health differently.

While this form of reporting heterogeneity may have limited consequences for tracking an individual's health over time, the consequences are much more serious for aggregated comparisons. For example, if poorer respondents, with otherwise identical medical conditions, report higher levels of SRH than richer respondents, then the true level of health inequality will be underestimated (Bago D'Uva et al. 2008; Murray et al. 2003). Equally, cross group comparisons of SRH, that fail to account for context, may be misleading as well as overlooking aspects of health and functioning that respondents themselves would prioritise (Hahn 1999). Therefore, if subjective health measures are used to inform the allocation of 
health resources, it is essential that reporting heterogeneity and its relationship with the measurement and determinants of SRH are well understood (Cubí-Mollá, et al. 2017).

In testament to its importance, a burgeoning literature providing empirical evidence of reporting heterogeneity has now emerged. In an American study, Idler (1993) found that elderly respondents persistently overestimate their health compared to other age groups. Lindeboom and van Doorslaer (2004) argued that, in undertaking self-assessment, respondents situate themselves alongside a particular reference group defined by age, gender and education. Similarly, Dowd and Zajacova (2010) found evidence of systematic income-based differences in SRH which were inconsistent with respect to objective biomarkers. Van Doorslaer and Gerdtham (2003), Lindeboom and van Doorslaer (2004), Etilé and Milcent (2006) and Bago D’Uva et al. (2008) present evidence that cultural and semantic understandings, as well as socioeconomic and demographic characteristics (e.g. age, education, gender, income), influence reporting heterogeneity.

As this literature was emerging, it began to draw influence from another strand of health research that related to the broader social and environmental determinants of health (WHO 2008). In this spirit, Etilé and Milcent (2006) and Bago D'Uva et al. (2008) argue that, independently of health, reporting behaviour is related more broadly to the environment in which individuals live. The former use information on regional mortality rates to capture local conditions, while the latter argue that the self-rating of health may be lower for individuals "living within a community in which a large proportion of the population suffers poor health" and, moreover, that an individual's willingness to tolerate ill-health is itself related to variations in access to effective health care. This captures the spirit of the work of Hildebrand and Van Kerm (2009) who examine the relationship between regional income inequality and individual self-rated health across a number of European Union countries.

The existing research has explored reporting heterogeneity for a range of developed and less-developed countries. Among the former are Germany (Schneider et al. 2012), France (Etilé and Milcent 2006), the UK (Hernández-Quevedo et al. 2004), Canada (Linderboom and van Doorslaer 2004) and, through a cross-country analysis, 10 European countries (Jürges 2007). Among the latter, Bago D’Uva et al. (2008) examine data for Indonesia, India and China. Russia, with its vast territory, geographical location between Europe and Asia, large multi-ethnic population, high level of socioeconomic inequality and variation in regional healthcare provision, represents an interesting case for studying reporting heterogeneity. To date, we have found only two Russia-based studies in this field, both published in Russian. The first (Kuchakov and Raskina 2017) uses anchoring vignettes, while a more recent paper (Kaneva and Baidin 2018) adopts an approach more similar to ours but does not attempt to capture the impact that regional environmental factors (e.g. regional socioeconomic characteristics) have on individual reporting heterogeneity. Yet, there is also evidence emerging of the relationship between regional level characteristics and individually reported outcomes for Russia. Carlson (2005) found that "regional health differences among men are in part explained by regional income differences" (p. 389). More recently, Lyytikainen and Kemppainen (2016) concurred, finding that persistent regional differences in self-rated health across Russia could not be explained by individual level differences. Watson et al. (2013), analyzing socio-economic determinants of obesity, noted that there are significant correlations between individual subjective health status and physical environments, including morbidity.

In this paper we therefore seek to extend the existing literature in two main ways. First, following Lindeboom and van Doorslaer (2004), we provide an evaluation of the nature of reporting heterogeneity in Russia. Second, following Etilé and Milcent (2006) and Bago D'Uva et al. (2008), we incorporate proxies for the individual's local social and economic 
environment on the basis that the latter may influence self-rating behaviour in systematic ways. In doing so, we draw out the vital connections between the voluminous literature that examines the link between social and environmental determinants of individual health (e.g. WHO 2008; Hilderbrand and van Kerm 2009; Marmot et al 2012) and the literature, referred to above, that seeks to distinguish true health effects from reporting effects. Our empirical results provide evidence that self-rating behaviour is systematically influenced by individual characteristics but also by regional socioeconomic characteristics. In contrast to other literature, we find that all of these effects are broadly similar across gender. While identifying the precise mechanisms linking aggregate level variables with either individual health outcomes or health reporting behaviour is beyond the scope of this paper, we suggest that both the relative income mechanism and a mechanism linking the cognitive process of choice with the sense of optimism that individuals' have for the local institutional environment are both plausible points of departure for future research.

The paper proceeds as follows. Drawing on Lindeboom and van Doorslaer (2004), in Sect. 2, we briefly summarise the formal approach for estimating and testing the presence of reporting heterogeneity in SRH and outline our identifying assumptions. Section 3 describes the Russian data that we use and presents the objective disease index employed in our identification strategy. Section 4 describes the results, which are then discussed in greater depth in Sect. 5. Section 6 concludes by identifying important policy implications and areas in which this research can be developed.

\section{Methods: Estimating Reporting Heterogeneity}

The essential logic underpinning this research is that, observed changes or differences in SRH between individuals could be due to changes in underlying 'true' health, or (and) could result from a measure-specific variation, holding true health constant. It is the latter variation which is referred to as reporting heterogeneity (Shmueli 2003; Gerry and Baidin 2017). The challenge of distinguishing these changes from fluctuations in true underlying health is well-established and there are various methods available. The WHO has advocated the use of anchoring vignettes (Tandon et al. 2003; Bago D’Uva et al. 2008; Kuchakov and Raskina 2017) which involve respondents in subjectively rating the health of the same set of hypothetical individuals. The responses to these vignettes are then used to anchor the respondents' self-rating of the components captured by the vignettes. In effect, by enabling inter-respondent comparability, this approach seeks to disconnect reporting behaviour from the underlying health concepts under investigation. As an alternative Lindeboom and van Doorslaer (2004) proposed a statistical model that facilitates the disaggregation of observed differences in SRH into (i) variation in underlying health and (ii) variation in reporting behaviour. In this approach, an objective health measure (rather than vignettes) anchors the responses and allows for cross group comparison. The major complication revolves around the identification problem. Lindeboom and Van Doorslaer (2004) and Etilé and Milcent (2006) provide excellent and detailed accounts of the issues around identification and so, below, we provide a summary outline of the model drawing attention to our key identification assumptions.

Taking a typical ordinal SRH question as our point of departure, define $H^{S}$ and $H^{*}$ as individual SRH and true underlying (but unobserved) individual health. For simplicity, we treat $H^{*}$ as a single (unobserved) health index and argue below that there are certain observable health measures which can be used to construct a direct proxy for this 
unobserved index. First, in estimating SRH, we define an ordered probit model for the categorical variable $H^{S}$ and its correspondence with the latent variable $H^{*}$ as:

$$
\begin{gathered}
H^{S}=j \Leftrightarrow c_{j-1}<H * \leqslant c_{j}, j=1, \ldots, n, \\
H^{*}=f\left(H^{0} ; \alpha\right)+X_{2}^{\prime} \beta_{2}+\varepsilon_{2} .
\end{gathered}
$$

where $H^{*}$ is a function of $X_{2}$, a set of factors affecting true unobserved health (e.g. environmental, medical and genetic factors) and $H^{0}$ is the unobserved initial health level. It follows from (2) that, if $X_{2}$ is empty, $H^{*}$ will correspond to the initial true health $H^{0}$.

The ordered probit model rests on the proportional odds (PO) assumption which means that, for each variable estimated in the model, the 'slope' estimates between each pair of outcomes across two response levels (e.g. SRH categories) are assumed to be the same regardless of which partition we consider (see Kim (2003) for a detailed analysis of the PO assumption). That is, the cut points $\left(c_{j}\right.$ in $\left.(1)\right)$, which are determined during the estimation of the model, are constant across the $n$ categories and are independent of the factors included in $X_{2}$. The set of variables in $X_{1}$ do not affect true health, $H^{*}$, but instead influence individual level health perceptions. As such, these become our key variables of interest in exploring reporting heterogeneity. Crucially, by relaxing the PO assumption the cut points are able to vary conditional on this set of perception influencing variables, $X_{1}$, which may also overlap with $X_{2}$. Thus, the formula for $c_{j}$ is:

$$
c_{j}=g_{j}\left(X_{1} ; \beta_{1 j}\right)=X_{1}^{\prime} \beta_{1 j}+\varepsilon_{1 j}, j=1, \ldots, n-1, c_{0}=-\infty, c_{n}=\infty .
$$

Substituting (2) and (3) into (1) and then combining (1) with (3) yields the generalized ordered probit model of (4)-(6) below. This model extends the previous one by incorporating an additional set of variables, associated with cut-point shifts. That is, the $\beta_{1 j}$ parameters are allowed to vary across the partitions. This allows us to distinguish between $f_{1}$, in (5), which captures the reporting heterogeneity determinants of SRH and $f_{2}$, in (6), which describes the determinants of true unobserved health. In combination, (5) and (6) therefore describe the relationship between true health $\left(H^{*}\right)$, self-rated health $\left(H^{S}\right)$, the factors influencing health reporting behaviour $\left(X_{1}\right.$, e.g. low socio-economic status) and the factors influencing true underlying health ( $X_{2}$, e.g. individual morbidities), with $\varepsilon_{1 j}$ and $\varepsilon_{2}$ representing random errors.

$$
\begin{gathered}
H^{S}=j \Leftrightarrow g_{j-1}\left(X_{1} ; \beta_{1, j-1}\right)-X_{2}^{\prime} \beta_{2}<f\left(H^{0} ; \alpha\right)+\varepsilon_{2} \leqslant g_{j}\left(X_{1} ; \beta_{1 j}\right)-X_{2}^{\prime} \beta_{2} . \\
H^{S}=f_{1}\left(H^{*}, X_{1}, \varepsilon_{1 j} ; \beta_{1 j}\right), \\
H^{*}=f_{2}\left(H^{0}, X_{2}, \varepsilon_{2} ; \beta_{2}\right) .
\end{gathered}
$$

Following Lindeboom and van Doorslaer, we focus on the existence of a cut-point shift and test the null hypothesis (7) that each $k$ factor influences each cut point $c_{j}$ in a similar way (so called 'index shift'). If the hypothesis is not rejected, we are unable to identify whether observed changes in SRH are due to an index shift (i.e. the $k$ factor belongs to $X_{2}$ and reflects changes in true underlying health) or if they reflect changes arising from reporting heterogeneity (i.e. the $k$ factor belongs to $X_{1}$ ). In contrast, rejection of (7) indicates that the $k$ factor effects the reporting thresholds in heterogenous ways and is therefore evidence of 
reporting heterogeneity (i.e. the $k$ factor belongs to at least $X_{1}$ ), since true underlying health is a linear function of its determinants (6) and so is only consistent with a parallel index shift.

$$
H_{0}: k_{j}=\text { const }, \quad \forall j .
$$

However, estimation of (4)-(6) and the testing of (7), does not entirely resolve the identification problem since, though it provides evidence of non-parallel cut-point shifts, it doesn't allow us to disentangle these from concurrent parallel cut-point shifts. For example, a localised environmental deterioration can affect true underlying health differentially (i.e. $X_{2}$, in (6)) while also provoking a generalised index shift (i.e. $X_{1}$, in (5)) as all residents become less optimistic about the future. In other words, the identification problem persists if we are unable to distinguish between variables in $X_{1}$, which affect reporting behaviour, and those in $X_{2}$, which affect only true underlying health.

In addressing this identification problem, Lindeboom and van Doorslaer note that "In practical situations one does not observe $H^{*}$ but a range of more objective measures. For example, whether an individual suffers from various health problems, diseases and self-related impediments in performing a range of daily activities" (Lindeboom and Doorslaer 2004, p. 1086). They argue that these variables are relevant only to underlying health outcomes and that, conditional on these effects, all other variables capture reporting heterogeneity. In this spirit, Etilé and Milcent (2006) construct a synthetic measure of clinical health, that is assumed to have no effect on the cut points, to "decompose the effect of income on SAH into an effect on clinical health (which is called a health production effect) and a reporting heterogeneity effect". In other words, the identification problem is resolved by including objective observable health variables in $X_{2}$ which, by assumption, are not present in $X_{1}$.

We mirror this approach by constructing an objective health index which we use as a proxy variable for unobservable true health $H^{*}$, conditional on which, we are able to interpret the impact of other variables on $H^{S}$ as reporting heterogeneity. More formally, we implement (4)-(6) by including an objective disease index $\left(\tilde{H}^{*} \sim H^{*}\right)$ as a proxy for $H^{*}$ and thus estimate the following generalized ordered random effects probit model (Pfarr et al. 2011) for our three category dependent variable:

$$
\begin{aligned}
& \operatorname{Pr}\left[H^{S}=1 \mid X_{1}, H^{*}=\tilde{H}^{*}\right]=1-F\left(X_{1} \beta_{11}+\tilde{H}^{*} \beta_{2}\right) \\
& \operatorname{Pr}\left[H^{S}=2 \mid X_{1}, H^{*}=\tilde{H}^{*}\right]=F\left(X_{1} \beta_{11}+\tilde{H}^{*} \beta_{2}\right)-F\left(X_{1} \beta_{12}+\tilde{H}^{*} \beta_{2}\right) . \\
& \operatorname{Pr}\left[H^{S}=3 \mid X_{1}, H^{*}=\tilde{H}^{*}\right]=F\left(X_{1} \beta_{12}+\tilde{H}^{*} \beta_{2}\right)
\end{aligned}
$$

where $F$ is the cumulative distribution function of the normal distribution. In estimating SRH (8) conditional on a proxy for true underlying health, it follows that the remaining explanatory power of the model is that associating each $k$ factor with a measure-specific variation in SRH (given true underlying health). That is, the coefficient for each $k$ factor represents the SRH reporting heterogeneity attributable to this factor, while the difference in the beta coefficients, across the partitions, represents the cut-point reporting heterogeneity discussed above (Schneider et al. 2012). In addition, in the panel data framework of the Russian data, we are also able to attenuate the effects of unobserved individual heterogeneity as conventionally captured by the random effects specification of the generalized ordered probit model. 


\section{Data}

This research draws principally on data from Phase II of the Russia Longitudinal Monitoring Survey-Higher School of Economics population survey (hereafter RLMS-HSE), yielding a nationally representative household sample from a repeated cross-section sample undertaken each autumn since 1994 (other than in 1997 and 1999). ${ }^{1}$ The survey collects extensive information on the socioeconomic, demographic, behavioural, attitudinal and health characteristics of the Russian population. ${ }^{2}$ We further augment these data with regional macroeconomic data, from the Russian State Statistical Agency, and public health expenditure, from The Federal Treasury, for the period 2006-2014. Our overall analysis is therefore based on a longitudinal dataset covering the period 2006-2014, corresponding to a total sample size of 113,676 (47,144 males and 66,532 females). Descriptive statistics of all the variables used in the analysis are presented in Appendix 1 and are further elaborated below.

As with all empirical work, our results are reliant on the correct specification of our estimates. The dependent variable, self-rated health-known to be a good predictor of future mortality (Bago D'Uva et al. 2008) — is based on a standard question, from the RLMSHSE, allowing respondents to choose between five possible answers: "very bad", "bad", "average", "good" and "very good". Interestingly, the answers "very bad" and "very good" attract very few responses, with less than $2 \%$ of respondents rating their health in these categories. We therefore merge the "bad" and "very bad" categories and the "good" and "very good" categories to produce a 3 -category dependent variable capturing good health $(=1)$, average health $(=2)$ and bad health $(=3)$.

The first subset of independent variables represents a standard set of survey-based variables in line with those used in previous theoretical and empirical studies of health, including age (Grossman 1972; Cairney 2000; Kim 2015), marital status (Bos and Bos 2007; Monden and Uunk 2013), education (Grossman 1972; Kaneva et al. 2018), (log) income (Grossman 1972; Lokshin and Ravallion 2008), settlement type (Gerry and Papadopoulos 2015) and regional location (Lyytikäinen and Kemppainen 2016). The second subset of independent variables are the regional macroeconomic indicators and are made up of (log) gross regional product, share of the labour force with tertiary education, regional morbidity (measured as the number of patients with newly diagnosed diseases per 100,000 population) and public expenditure on healthcare. While it is the case that the range of regional level indicators available is rather narrow for Russia, we focused our selection of variables on those areas that provided symmetry with the factors we know are important at the individual level (e.g. income, education, health). We draw these aggregate indicators, covering 80 Russian regions, from the Federal State Statistic Service of the Russian Federation (Rosstat) yearbooks (Regions of Russia 2017; Health in Russia 2017). ${ }^{3}$ The inclusion of these variables marks one of our core contributions and recognises the seminal literature

\footnotetext{
1 The RLMS-HSE is a survey conducted by Higher School of Economics and ZAO Demoscope together with Carolina Population Center, University of North Carolina at Chapel Hill and the Institute of Sociology RAS (details at http://www.cpc.unc.edu/projects/rlms-hse (English) and http://www.hse.ru/org/hse/rlms (Russian).

2 The RLMS-HSE survey data has been widely used and the Economics of Transition (2015) journal devoted a special issue showcasing the survey data and identifying strengths and weaknesses.

3 Ideally, we would incorporate community level indicators but unfortunately, Rosstat does not report such data.
} 
on the social determinants of individual health (WHO 2008; Marmot et al. 2012). This literature identifies - among other things - the crucial role played by the welfare system, the tax framework, gross domestic product and other socio-economic, cultural, political and environmental conditions in shaping individual health experiences and outcomes.

Finally, we turn to the objective disease index, for which there are several plausible approaches identified in the literature (Schneider et al. 2012; Pfarr et al. 2012). The two fundamental requirements for this index are firstly, availability of objective health variables which are relevant only to the determination of true health and; secondly, that the index is “correctly specified as a homogenous function of covariates" (Bago D'Uva et al. 2008, p.357). If these conditions are satisfied then, by including the index in the estimate of (8), we can net out the true health impact on SRH and observe reporting heterogeneity through the remaining covariates. The RLMS-HSE data contains information on six diseases diagnosed by a medical specialist: diabetes, myocardial infarction, stroke, anaemia, hepatitis and tuberculosis. The index, scaled to take values between 0 and 100, is constructed from the predicted values of a bivariate random effects panel probit regression which includes the six diagnosed diseases as independent variables regressed on a binary variable indicating whether the respondent has experienced health problems in the last 30 days.

In implementing Eq. (8) we estimate the models separately for males and females. First, prior research shows that there are substantial differences in health reporting between genders in Russia (Kaneva et al. 2018) that can bias the construction of the objective disease index. Second, the existing literature also points to systematic gender differences in reporting behaviour: Murray et al (2003) suggest that "men may be more likely to deny declines in health so that their cut-points may be systematically shifted as compared to women" (p. 710) while Schneider et al. (2012) provide quantitative estimates of the gender differences in the generalized ordered probit model for SRH.

\section{Results}

Before turning to the results of estimating Eq. (8), we briefly present the outcome of the bivariate random effects panel probit regressions used to generate the objective health index (Appendix 2). In line with the discussion above, we estimate these models separately for males (ind6m) and females (ind6f) over the period 2006-2014. Appendix 2 provides very strong evidence of a positive relationship between the diagnosed diseases and the recent reporting of health problems, with a higher index score for females compared with males (Appendix 1). The latter is consistent with the means for the two dependent variables, which also show females reporting less good health than males. The respective indices are also strongly significant and with the expected sign in the SRH estimates.

Turning to the results of the SRH estimates, Table 1 presents the regression results separately for males and females, with two sets of estimates in each case. In the first, category 1 (good health) is contrasted with categories 2 and 3 (average health and bad health) to produce a set of $\beta_{\mathrm{k} 1}$ estimates which represent the impact that a unit change in the independent variable $k$ has on the probability of being in bad or average health rather than good health. In the second, category 3 (bad health) is contrasted with categories 1 and 2 (good health and average health) to produce a set of $\beta_{\mathrm{k} 2}$ estimates which capture the impact of a unit change in the independent variable $k$ on the probability of being in bad health rather than average and good health. Where the coefficients are identical, we only report them in the first column of each case. Since, through the objective disease index, the estimates 


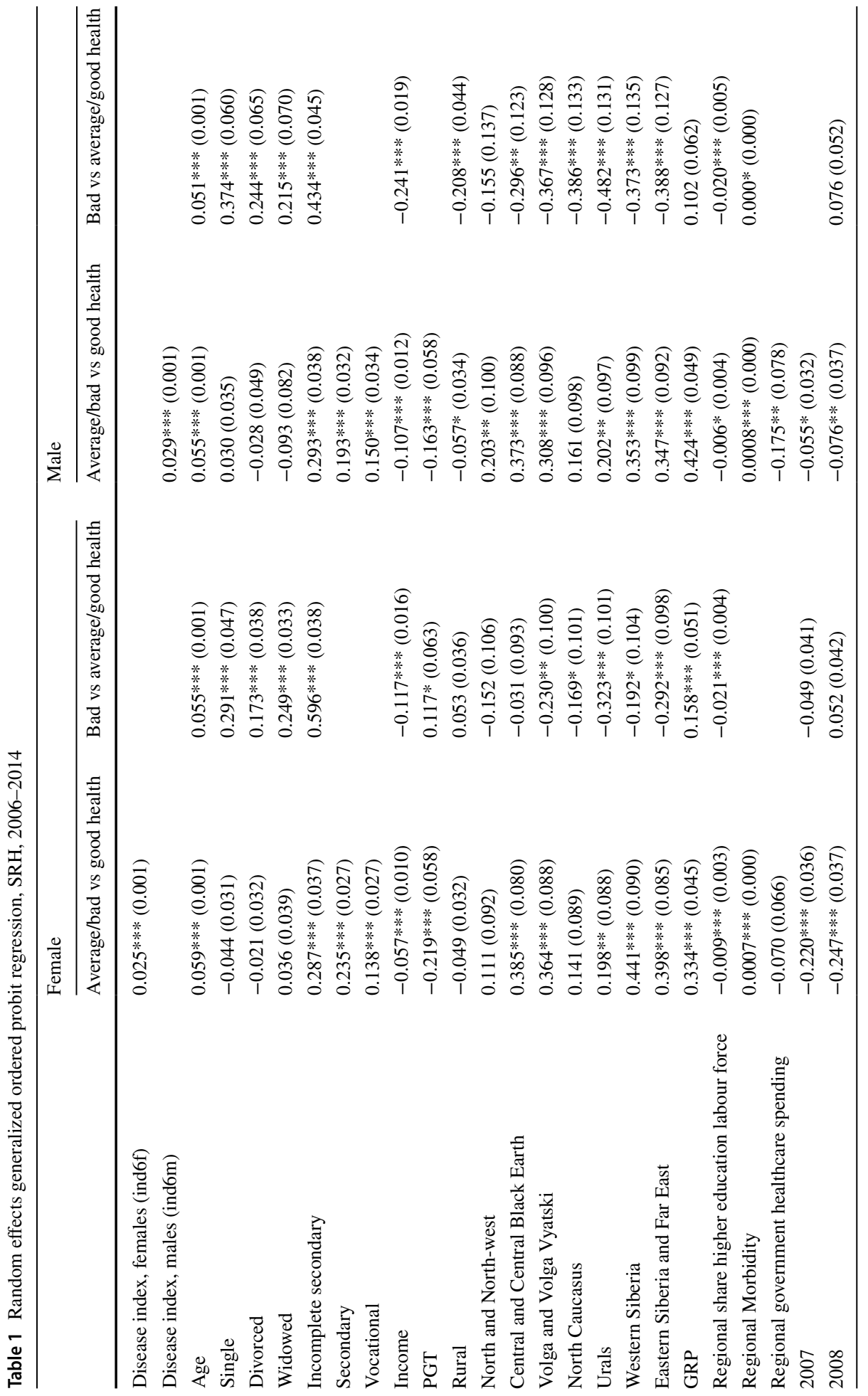




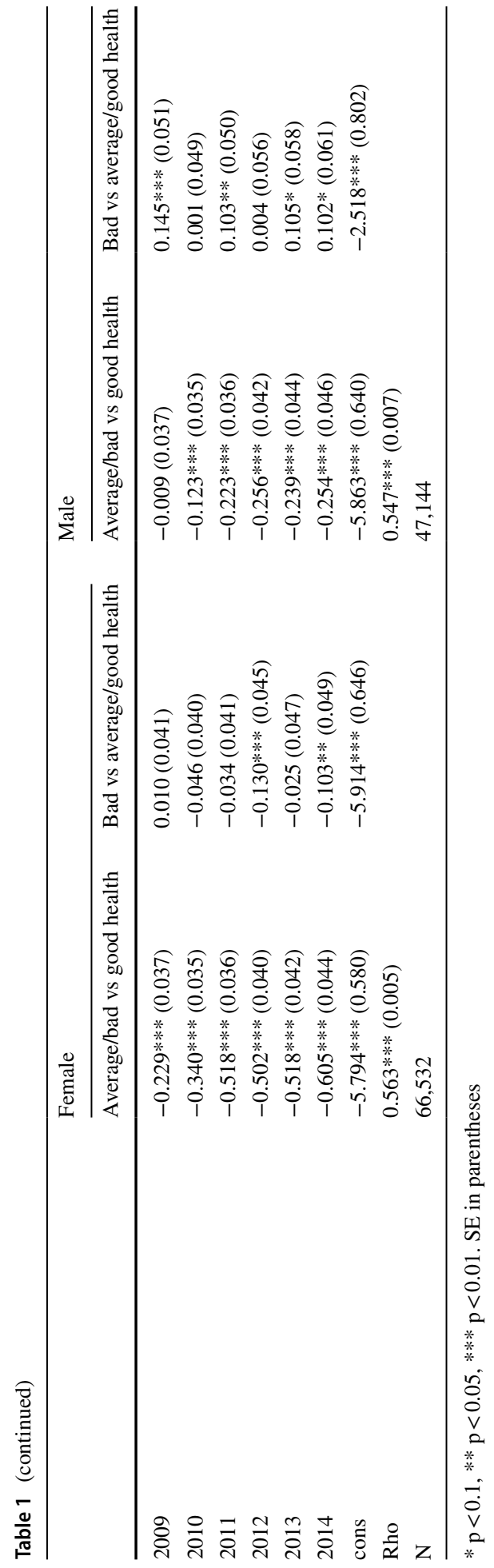


Table 2 Average marginal effects for females, 2006-2014

\begin{tabular}{|c|c|c|c|}
\hline & $\begin{array}{l}\text { Probability } 1=\text { good } \\
\text { health; dy/dx }\end{array}$ & $\begin{array}{l}\text { Probability } 2=\text { ave. } \\
\text { health; dy/dx }\end{array}$ & $\begin{array}{l}\text { Probability } 3=\text { bad } \\
\text { health; dy/dx }\end{array}$ \\
\hline Age & $-0.010 * * *(0.000)$ & $0.003 * * *(0.000)$ & $0.007 * * *(0.000)$ \\
\hline Single & $0.007(0.005)$ & $-0.043 * * *(0.007)$ & $0.036 * * *(0.006)$ \\
\hline Divorced & $0.003(0.005)$ & $-0.025 * * *(0.006)$ & $0.021 * * *(0.005)$ \\
\hline Widowed & $-0.006(0.007)$ & $-0.025 * * *(0.007)$ & $0.031 * * *(0.004)$ \\
\hline Incomplete secondary & $-0.049 * * *(0.006)$ & $-0.025 * * *(0.006)$ & $0.073 * * *(0.005)$ \\
\hline Income & $0.010 * * *(0.002)$ & $0.005 * *(0.002)$ & $-0.014 * * *(0.002)$ \\
\hline PGT & $0.037 * * *(0.010)$ & $-0.052 * * *(0.009)$ & $0.014 *(0.008)$ \\
\hline Rural & $0.008(0.005)$ & $-0.015 * * *(0.005)$ & $0.007(0.004)$ \\
\hline North and North-west & $-0.019(0.016)$ & $0.038 * *(0.017)$ & $-0.019(0.013)$ \\
\hline Central and Central Black Earth & $-0.065 * * *(0.014)$ & $0.069 * * *(0.014)$ & $-0.004(0.011)$ \\
\hline Volga and Volga Vyatski & $-0.062 * * *(0.015)$ & $0.090 * * *(0.015)$ & $-0.028 * *(0.012)$ \\
\hline North Caucasus & $-0.024(0.015)$ & $0.045^{* * *}(0.015)$ & $-0.021 *(0.012)$ \\
\hline Urals & $-0.034 * *(0.015)$ & $0.073 * * *(0.016)$ & $-0.040 * * *(0.012)$ \\
\hline Western Siberia & $-0.075^{* * *}(0.015)$ & $0.099 * * *(0.016)$ & $-0.024 *(0.013)$ \\
\hline Eastern Siberia and Far East & $-0.068 * * *(0.014)$ & $0.104 * * *(0.016)$ & $-0.036^{* * *}(0.012)$ \\
\hline GRP & $-0.057 * * *(0.008)$ & $0.037 * * *(0.007)$ & $0.019 * * *(0.006)$ \\
\hline $\begin{array}{l}\text { Regional share higher education } \\
\text { labour force }\end{array}$ & $0.002 * * *(0.001)$ & $0.001(0.001)$ & $-0.003 * * *(0.000)$ \\
\hline Regional morbidity $(* 1000)$ & $-0.120 * * *(0.017)$ & $0.032 * * *(0.047)$ & $0.087 *(0.012)$ \\
\hline 2008 & $0.042 * * *(0.006)$ & $-0.048 * * *(0.008)$ & $0.006(0.005)$ \\
\hline 2009 & $0.039 * * *(0.006)$ & $-0.040 * * *(0.008)$ & $0.001(0.005)$ \\
\hline 2010 & $0.058 * * *(0.006)$ & $-0.052^{* * *}(0.007)$ & $-0.006(0.005)$ \\
\hline 2011 & $0.088 * * *(0.006)$ & $-0.084 * * *(0.008)$ & $-0.004(0.005)$ \\
\hline 2012 & $0.085^{* * *}(0.007)$ & $-0.069^{* * *}(0.008)$ & $-0.016^{* * *}(0.006)$ \\
\hline 2013 & $0.088 * * *(0.007)$ & $-0.085^{* * *}(0.008)$ & $-0.003(0.006)$ \\
\hline 2014 & $0.103 * * *(0.007)$ & $-0.090 * * *(0.008)$ & $-0.013 * *(0.006)$ \\
\hline
\end{tabular}

$* \mathrm{p}<0.1, * * \mathrm{p}<0.05, * * * \mathrm{p}<0.01$. SE in parentheses

condition for true health, we are able to identify the way in which the explanatory variables influence the self-rating process at different points of the SRH distribution. Tables 2 and 3 present the average marginal effects for each level of SRH, depicting how the probability of choosing a particular outcome responds to a marginal change in the explanatory variable. Table 1 therefore presents the full results for both constrained and unconstrained variables while Tables 2 and 3 present the marginal effects for the variables where the coefficients are not identical.

We start by presenting the results of the first group of variables (i.e. the socioeconomic and demographic variables used in related literature), before moving on to present our main variables of interest - the aggregate level variables. For both men and women, each year of additional age is associated with an approximate 1 percentage point reduction in the likelihood of reporting good health and a consequent smaller but significant likelihood of reporting bad or average health. Being unmarried decreases the likelihood of reporting good health by 2-4 percentage points, depending on whether single, divorced or widowed. Both age and marital status are associated with cut-point 
Table 3 Average marginal effects for males, 2006-2014

\begin{tabular}{|c|c|c|c|}
\hline & $\begin{array}{l}\text { Probability } 1=\text { good } \\
\text { health; dy/dx }\end{array}$ & $\begin{array}{l}\text { Probability } 1=\text { ave } \\
\text { health; dy/dx }\end{array}$ & $\begin{array}{l}\text { Probability } 1=\text { bad } \\
\text { health; dy/dx }\end{array}$ \\
\hline Age & $-0.012 * * *(0.000)$ & $0.007 * * *(0.000)$ & $0.004 * * *(0.000)$ \\
\hline Single & $-0.006(0.008)$ & $-0.027 * * *(0.008)$ & $0.033 * * *(0.005)$ \\
\hline Divorced & $0.006(0.011)$ & $-0.028 * * *(0.010)$ & $0.022 * * *(0.006)$ \\
\hline Widowed & $0.020(0.018)$ & $-0.039 * *(0.017)$ & $0.019 * * *(0.006)$ \\
\hline Incomplete secondary & $-0.063 * * *(0.008)$ & $0.025 * * *(0.007)$ & $0.038 * * *(0.004)$ \\
\hline Income & $0.023 * * *(0.003)$ & $-0.002(0.003)$ & $-0.021 * * *(0.002)$ \\
\hline PGT & $0.035 * * *(0.012)$ & $-0.021 * * *(0.007)$ & $-0.014 * * *(0.005)$ \\
\hline Rural & $0.012 *(0.007)$ & $0.006(0.007)$ & $-0.018 * * *(0.004)$ \\
\hline North and North-west & $-0.044 * *(0.021)$ & $0.057 * * *(0.021)$ & $-0.014(0.012)$ \\
\hline Central and Central Black Earth & $-0.080 * * *(0.019)$ & $0.106 * * *(0.018)$ & $-0.026 * *(0.011)$ \\
\hline Volga and Volga Vyatski & $-0.066 * * *(0.021)$ & $0.098 * * *(0.019)$ & $-0.032 * * *(0.011)$ \\
\hline North Caucasus & $-0.034(0.021)$ & $0.068 * * *(0.020)$ & $-0.034 * * *(0.012)$ \\
\hline Urals & $-0.043 * *(0.021)$ & $0.086 * * *(0.020)$ & $-0.042 * * *(0.012)$ \\
\hline Western Siberia & $-0.076 * * *(0.021)$ & $0.109 * * *(0.020)$ & $-0.033 * * *(0.012)$ \\
\hline Eastern Siberia and Far East & $-0.074 * * *(0.020)$ & $0.109 * * *(0.019)$ & $-0.034 * * *(0.011)$ \\
\hline GRP & $-0.091 * * *(0.011)$ & $0.082 * * *(0.009)$ & $0.009(0.005)$ \\
\hline $\begin{array}{l}\text { Regional share higher education } \\
\text { labour force }\end{array}$ & $0.001 *(0.001)$ & $0.000(0.001)$ & $-0.002 * * *(0.000)$ \\
\hline Regional morbidity $(* 1000)$ & $-0.167 * * *(0.026)$ & $0.140 * * *(0.024)$ & $0.027 *(0.014)$ \\
\hline 2008 & $0.016 * *(0.008)$ & $-0.023 * * *(0.008)$ & $0.007(0.005)$ \\
\hline 2009 & $0.002(0.008)$ & $-0.015^{*}(0.008)$ & $0.013 * * *(0.005)$ \\
\hline 2010 & $0.026 * * *(0.008)$ & $-0.026 * * *(0.008)$ & $0.000(0.004)$ \\
\hline 2011 & $0.048 * * *(0.008)$ & $-0.057 * * *(0.008)$ & $0.009 * *(0.004)$ \\
\hline 2012 & $0.055 * * *(0.009)$ & $-0.055^{* * *}(0.008)$ & $0.000(0.005)$ \\
\hline 2013 & $0.051 * * *(0.009)$ & $-0.061 * * *(0.009)$ & $0.009 *(0.005)$ \\
\hline 2014 & $0.055^{* * * *}(0.010)$ & $-0.064 * * *(0.009)$ & $0.009 *(0.005)$ \\
\hline
\end{tabular}

$* \mathrm{p}<0.1, * * \mathrm{p}<0.05, * * * \mathrm{p}<0.01 . \mathrm{SE}$ in parentheses

reporting heterogeneity, since the parallel-lines assumption is rejected and while, for age, the lower probability of reporting good health is balanced by the higher probability of reporting both average and bad health, not being married impacts particularly on the reporting of bad (rather than average or good) health.

Secondary and vocational education, compared to higher education, are strongly significant and associated, as expected, with less good SRH. The size of the effect is similar for males and females and, representing an index shift, is identical across the SRH distribution. However, we find strong evidence that having the lowest level of education is linked with cut-point reporting heterogeneity: females and males are 5-6 (4-7) percentage points less (more) likely to report good (bad) health in this category. Interestingly, females are also less likely to report average health and therefore more inclined to report bad health (7 percentage points), whereas males are more likely to report average health and therefore only 3.8 percentage points more likely to report bad health. In a similar vein to education, income drives reporting behaviour and is positively associated 
with good health and negatively associated with reporting bad health although in both cases the effects are roughly twice as large for males.

The regional and settlement type variables are also associated with cut-point reporting heterogeneity and in differing ways for males and females. For males, being outside of urban areas is associated with a significant increase in the propensity to report good health and a corresponding decrease in the likelihood of reporting bad health. Being outside of Moscow and St Petersburg increases the likelihood of reporting average health and substantially lowers the probability of reporting either good or bad health. For women, the likelihood of reporting average health is also significantly higher outside of Moscow and St Petersburg, while being outside of urban areas per se strongly reduces the likelihood of reporting average health; although, for good and bad health reporting, there is no significant difference between urban and rural areas. In contrast to males, females in small urban areas are more likely to report bad health.

Turning now to the aggregate level variables, we find that regional government health spending, for which the parallel lines assumption is not rejected, is associated with better SRH for males but with no significant impact on female SRH. For the remaining three aggregate variables there is evidence of cut-point reporting heterogeneity. First, increases in the level of regional morbidity are strongly linked with a lower (higher) likelihood of reporting good (bad and average) health. Second, for both males and females, higher gross regional product reduces the probability of reporting good health substantially-by 9 percentage points and 6 percentage points respectively. For females there is a corresponding 4 percentage points ( 2 percentage points) increase in the likelihood of reporting average (bad) health, while for males there is an 8 percentage points increase in the probability of reporting average health, but no significant impact on the probability of reporting bad health. The larger the share of the labour force with higher education, the more likely are both females and males to evaluate their health positively and, correspondingly, the lower the likelihood of reporting bad SRH. Finally, the probability of reporting good health each year, increased by between 4 and 10 percentage points per year for females and between 2 and 6 percentage points for males.

As explained in the previous section, in arguing that it is possible to identify reporting heterogeneity, we lean heavily on the reliability of the disease index. As a robustness check therefore, and within the constraints of the RLMS-HSE survey data, we repeat the above exercise with an expanded disease index incorporating three additional self-diagnosed conditions, which we consider are the least likely to be falsely self-diagnosed: oncological disease, allergies and joint disease. Information on these health conditions is only available from 2010 and therefore we have a substantially reduced sample, representing about $40 \%$ of the full sample. The results of this exercise are presented in Appendix 3 and show relatively little qualitative difference to our main Table 1 results. In particular, the sign and scale of the coefficients is reassuringly similar, and the evidence of reporting heterogeneity is substantively overlapping. We are therefore as confident as we can be that our objective disease index is a reasonable proxy for true underlying health.

\section{Discussion}

The empirical approach adopted in this paper seeks to identify reporting heterogeneity by controlling for true underlying health via the inclusion of an objective health index in the estimation of SRH. In an echo of the ground-breaking literature on the social determinants 
of health, our main empirical contribution is to further augment the estimated model of SRH by incorporating regional socioeconomic characteristics. Specifically, we argue that, it is not only individual characteristics that can impact both real underlying health and selfreported health, but that aggregate, environmental characteristics also have this attribute. To our knowledge, this fact has been overlooked to date in the reporting heterogeneity literature. However, the logic is powerful; for example, a large increase in public health spending may directly affect the health of those benefitting from the expenditure but it is likely also to have an indirect reporting effect through its impact on the confidence that the population have in the public health environment.

We argue that there are at least three broad channels through which an 'aggregate' reporting effect might operate. First, is the 'immediate effects' channel, which mirrors the manner in which individual characteristics, such as income, may impact on reporting. For example, reductions in pollution, or improvements in weather (like increases in personal income) can immediately lift an individual's mood in ways that impact upon their SRH. Second, the 'communication channel' captures the impact that interaction with third parties can have on self-perceived health. For example, working in an environment in which co-workers are known to be unwell, impacts - through the cognitive reorientation of riskon the individual's self-assessment. Finally, the 'relative position' channel captures the impact that changes in a comparative position can have on an individual. For example, relocating a hypothetical individual from a high-income environment into a lower income environment, in which their relative income is now much higher, may impact upon SRH and well-being, independently of any objective changes in underlying health.

Turning to our findings, consistent with the 'relative position' channel, an increase in regional income results in a deterioration in SRH beyond its effect on underlying health. In other words, as the relative income of the individual falls, some cognitive adjustment takes place which links the perception of being poorer with a less optimistic assessment of health. This macro level relationship therefore operates in precisely the opposite direction to the individual micro relationship. That is, while increases in individual income provide enhanced opportunities for accessing health care, holding individual income constant, a deterioration in relative income is associated with a significantly reduced likelihood of reporting good health, a greater probability of reporting average health and, for females only, an increased likelihood of reporting bad health. This is potentially a very important finding as it suggests that, beyond individual socioeconomic and demographic characteristics, an individual's relative standing in their local economy conditions their SRH status. While consistent with a rich and well-established literature examining the link between income inequality and health outcomes (e.g. Gravelle and Sutton 2009; Hilderbrand and van Kerm 2009; Wilkinson and Pickett 2010), we contend that, in the first instance, the important mechanism linking aggregate social effects with SRH is a reporting effect. Understanding the relationship between this reporting effect and subsequent changes in underlying health conditions (e.g. via status anxiety) is a matter for further research.

The second important aggregate finding relates to the positive impact that the local education level has on SRH. This is consistent with the communication channel outlined above. By operating in a higher human capital environment, either at work or in local neighbourhoods, the individual internalises some of the external higher education effects. This education effect then augments the, separate, positive relationship between individual education and SRH, which is consistent with the so-called education gradient, implying an association between health and education, with the latter endowing people with the knowledge and individual agency to improve their health. 
Turning to the aggregate health indicators, while we don't find evidence of cutpoint reporting heterogeneity in the case of regional government healthcare spending, our results suggest that it does impact on SRH-a finding that merits further investigation. We find strong evidence that higher regional morbidity levels are associated with lower levels of SRH, even after controlling for individual health through the objective health index. In other words, the higher the levels of illness prevailing in the surrounding area are, the less positive individuals feel about their own health, independently of their objective underlying health. Once again, we argue that this is more likely to be a consequence of cognitive recalibration (e.g. regarding the perception of risks) rather than reflecting a necessary link with objective underlying health conditions. That is, the effect operates via the 'communication channel'.

Briefly, we also confirm that, even with the inclusion of the aggregate factors, the results relating to the individual level characteristics are consistent with both the related literature and with previous evidence for Russia (Kaneva and Baidin 2018). There is strong evidence that age contributes to reporting heterogeneity and that, independent of objective health, each year that passes increases the likelihood of reporting bad health and decreases the likelihood of reporting good health. If this is the case then recalibrating age-specific health expectations could be an important policy instrument (see, for example, Kaneva et al. 2019). In concert with earlier research for Russia (Sinelnikov 2011) our results also show that being in a relationship is likely to decrease the probability of reporting bad health (and average health for men). This could stem from a positive expectation that being in a partnership will offer both financial and emotional support and therefore reduce feelings of vulnerability. Of course, it is plausible that healthier individuals self-select into successful relationships and if this is the case then the additional reporting effect is particularly interesting. Our results also show that individuals outside of Moscow and St Petersburg are less likely to evaluate their health as either good or bad, suggesting that there is less inequality in expectation, understanding and reality than in the metropolis areas of Russia's two big cities.

Finally, one interesting divergence relates to gender. Broadly speaking, the variables determining reporting heterogeneity in these Russian data are the same for males and females. While this is consistent with Lindeboom and van Doorslaer (2004), it contrasts with other research (e.g. Schneider et al. 2012) suggestive of more substantive gender differences. In Russia, as in most countries, we know that there are large reporting differences between males and females and so, because we can't explain this through observed characteristics, this research suggests that gender may capture some other, perhaps culturally shaped, behavioural traits and attitudes which also merit further research.

This brings us to consider the limitations of the study. Foremost among these is that we are not able, with these data, to do much beyond speculate as to the underlying mechanisms that drive the data generating process. Secondly, we are also constrained by the data with regards to the objective health indices. Ideally, we would like to have included still more 'objective' health data including blood pressure, grip strength, biomarkers and the like. Given the importance of the objective index for resolving the identification problem in the estimated model, this is an obvious caveat. Thirdly, the aggregated data are not at the optimum level of aggregation, but they are the only such variables available for Russia at this time. Finally, the results we present are associations and the claims we can make to establishing causality are inevitably limited. All this having been said, we are confident that our research provides an important contribution to the literature on reporting heterogeneity in SRH and motivates a number of further interesting lines of enquiry. 


\section{Conclusion}

Using an objective health index as a proxy for true health enables us to distinguish between explanatory variables which give rise to reporting heterogeneity in SRH. We find that the causes of observed reporting heterogeneity are broadly similar for males and females and that therefore, since females report substantially higher SRH than males, gender itself is an important dimension underscoring reporting heterogeneity in Russia. For both males and females, socio-economic, demographic and settlement/ region characteristics all give rise to important forms of reporting heterogeneity. Notwithstanding these important additions to the literature, our single most important contribution is to provide the first assessment of the relationship between the broader social and economic environment and SRH. We show that aggregate level environmental characteristics can not only impact directly on health, but can also separately and systematically influence reporting behaviour, conditional on underlying true health. We provide some tentative suggestions as to the possible mechanisms at play, which augment those identified in the literature linking income inequality per se with social and health outcomes (e.g. relative income hypothesis, status anxiety etc.). Further work is necessary to disentangle what appear to be reporting effects from what might be more 'real' effects.

Funding This work was supported by the Russian Presidential Academy of National Economy and Public Administration, Moscow (RANEPA).

Open Access This article is licensed under a Creative Commons Attribution 4.0 International License, which permits use, sharing, adaptation, distribution and reproduction in any medium or format, as long as you give appropriate credit to the original author(s) and the source, provide a link to the Creative Commons licence, and indicate if changes were made. The images or other third party material in this article are included in the article's Creative Commons licence, unless indicated otherwise in a credit line to the material. If material is not included in the article's Creative Commons licence and your intended use is not permitted by statutory regulation or exceeds the permitted use, you will need to obtain permission directly from the copyright holder. To view a copy of this licence, visit http://creativecommons.org/licenses/by/4.0/.

\section{Appendix 1: Descriptive statistics, 2006-2014}

\begin{tabular}{|c|c|c|c|c|c|}
\hline \multirow[t]{2}{*}{ Variable } & \multirow[t]{2}{*}{ Definition } & \multicolumn{2}{|l|}{ Males } & \multicolumn{2}{|l|}{ Females } \\
\hline & & Mean & SD & Mean & SD \\
\hline \multicolumn{6}{|c|}{ Dependent variable } \\
\hline SRH & $\begin{array}{l}\text { Self-rated health }(1=\text { good; } \\
2=\text { average; } 3=\text { bad })\end{array}$ & 1.696 & 0.643 & 1.908 & 0.657 \\
\hline \multicolumn{6}{|c|}{ RLMS-HSE independent variables: continuous } \\
\hline Age & Age in years & 43.199 & 16.826 & 48.043 & 18.568 \\
\hline Lninc_r $r$ & $\begin{array}{l}\text { Natural logarithm of real } \\
\text { income in the last } 30 \text { days } \\
\text { (2006 prices) }\end{array}$ & 8.262 & 0.912 & 7.939 & 0.892 \\
\hline Ind6m & $\begin{array}{l}\text { Objective disease index for } \\
\text { males for } 6 \text { diagnosed } \\
\text { diseases }\end{array}$ & 22.617 & 11.404 & & \\
\hline
\end{tabular}




\begin{tabular}{|c|c|c|c|c|c|}
\hline \multirow[t]{2}{*}{ Variable } & \multirow[t]{2}{*}{ Definition } & \multicolumn{2}{|l|}{ Males } & \multicolumn{2}{|l|}{ Females } \\
\hline & & Mean & SD & Mean & SD \\
\hline Ind $6 f$ & $\begin{array}{l}\text { Objective disease index for } \\
\text { females for } 6 \text { diagnosed } \\
\text { diseases }\end{array}$ & & & 40.999 & 12.462 \\
\hline Ind $9 m$ & $\begin{array}{l}\text { Objective disease index for } \\
\text { males (Ind6m plus cancer, } \\
\text { allergies and joint diseases) }\end{array}$ & 22.782 & 17.204 & & \\
\hline Ind $9 f$ & $\begin{array}{l}\text { Objective disease index } \\
\text { for females (Ind6m plus } \\
\text { cancer, allergies and joint } \\
\text { diseases) }\end{array}$ & & & 42.155 & 21.458 \\
\hline \multicolumn{6}{|c|}{ RLMS-HSE independent variables: dummy variables } \\
\hline Single & $1=$ single & 0.167 & 0.373 & 0.128 & 0.334 \\
\hline Divorced & $1=$ divorced & 0.048 & 0.214 & 0.122 & 0.327 \\
\hline Widowed & $1=$ widow $/$ widower & 0.028 & 0.166 & 0.203 & 0.402 \\
\hline Married* & $1=$ married & 0.756 & 0.429 & 0.547 & 0.498 \\
\hline Incomplete secondary & $\begin{array}{l}1=\text { incomplete secondary } \\
\text { education }\end{array}$ & 0.217 & 0.412 & 0.193 & 0.395 \\
\hline Secondary & $1=$ secondary education & 0.373 & 0.484 & 0.266 & 0.442 \\
\hline Vocational & $1=$ vocational education & 0.201 & 0.401 & 0.285 & 0.452 \\
\hline Higher Ed* & $1=$ higher/graduate education & 0.208 & 0.406 & 0.256 & 0.436 \\
\hline$P G T$ & $1=$ urban type settlement & 0.063 & 0.242 & 0.062 & 0.241 \\
\hline Rural & $1=$ rural settlement & 0.262 & 0.440 & 0.245 & 0.430 \\
\hline Urban* & $1=$ town & 0.676 & 0.468 & 0.694 & 0.461 \\
\hline North and North West & $\begin{array}{l}1=\text { resident in North or } \\
\text { North-western }\end{array}$ & 0.062 & 0.241 & 0.070 & 0.255 \\
\hline Central & $\begin{array}{l}1=\text { resident in Central or } \\
\text { Central Black Earth }\end{array}$ & 0.193 & 0.395 & 0.193 & 0.395 \\
\hline Volga & $\begin{array}{l}1=\text { resident in Volga or } \\
\text { Volga-Vyatski }\end{array}$ & 0.176 & 0.381 & 0.173 & 0.378 \\
\hline North Caucasus & $\begin{array}{l}1=\text { resident in North Cau- } \\
\text { casus }\end{array}$ & 0.141 & 0.348 & 0.128 & 0.334 \\
\hline Urals & $1=$ resident in Ural & 0.140 & 0.347 & 0.143 & 0.350 \\
\hline Western Siberia & $1=$ resident in West Siberia & 0.089 & 0.284 & 0.089 & 0.285 \\
\hline Eastern Siberia and Far East & $\begin{array}{l}1=\text { resident in East Siberia or } \\
\text { Far East }\end{array}$ & 0.092 & 0.289 & 0.089 & 0.285 \\
\hline Capital* & $\begin{array}{l}1=\text { resident in Moscow or St } \\
\text { Petersburg }\end{array}$ & 0.106 & 0.308 & 0.115 & 0.319 \\
\hline \multicolumn{6}{|l|}{ Macroeconomic variables } \\
\hline$G R P p c \_l n$ & $\begin{array}{l}\text { Real gross regional product } \\
\text { per capita ( } 2006 \text { prices) } \\
\text { (log) }\end{array}$ & 11.936 & 0.537 & 11.956 & 0.539 \\
\hline
\end{tabular}




\begin{tabular}{|c|c|c|c|c|c|}
\hline \multirow[t]{2}{*}{ Variable } & \multirow[t]{2}{*}{ Definition } & \multicolumn{2}{|l|}{ Males } & \multicolumn{2}{|l|}{ Females } \\
\hline & & Mean & SD & Mean & SD \\
\hline Regional morbidity & $\begin{array}{l}\text { Patients first diagnosed with } \\
\text { an illness per } 100000 \\
\text { population }\end{array}$ & 769.486 & 148.427 & 770.728 & 145.992 \\
\hline Labour force & $\begin{array}{l}\text { Share of labour force with } \\
\text { tertiary education }\end{array}$ & 29.090 & 7.444 & 29.291 & 7.569 \\
\hline Regional health spending & $\begin{array}{l}\text { Public expenditure on } \\
\text { healthcare reimbursement } \\
\text { for OMS }\end{array}$ & 8.768 & 0.361 & 8.778 & 0.364 \\
\hline Observations & & $N=47,144$ & & $N=66,532$ & \\
\hline
\end{tabular}

*Denotes reference category.

\section{Appendix 2: Random effects panel probit regression, health problems in last 30 days, 2006-2014}

\begin{tabular}{|c|c|c|c|c|}
\hline & \multicolumn{2}{|l|}{ Males } & \multicolumn{2}{|l|}{ Females } \\
\hline & Coefficient & SD & Coefficient & SD \\
\hline Diabetes & $0.737 * * *$ & 0.048 & $0.798 * * *$ & 0.029 \\
\hline Myocardial infarction & $1.039 * * *$ & 0.054 & $0.908 * * *$ & 0.057 \\
\hline Stroke & $1.078^{* * * *}$ & 0.059 & $0.815^{* * *}$ & 0.053 \\
\hline Anaemia & $0.845^{* * *}$ & 0.071 & $0.440 * * *$ & 0.027 \\
\hline Hepatitis, jaundice, Botkin disease & $0.631 * * *$ & 0.079 & $0.557 * * *$ & 0.099 \\
\hline Tuberculosis & $0.221 * * *$ & 0.035 & $0.288 * * *$ & 0.033 \\
\hline Constant & $-0.877 * * *$ & 0.011 & $-0.371 * * *$ & 0.009 \\
\hline $\begin{array}{l}\text { Wald } \chi^{2}(6) \\
\text { Prob }>\chi^{2}\end{array}$ & $\begin{array}{l}1363.66 \\
{[0.0000]}\end{array}$ & & $\begin{array}{l}1784.19 \\
{[0.0000]}\end{array}$ & \\
\hline$N$ & 56,816 & & 77,165 & \\
\hline Number of groups & 14,331 & & 18,098 & \\
\hline
\end{tabular}

$* * *$ Denotes significance at $1 \%$ level.

\section{Appendix 3: Random effects generalized ordered probit regression, SRH, 2010-2014}

\begin{tabular}{llllll}
\hline & Female & & Male & \\
\cline { 2 - 3 } \cline { 5 - 6 } & $\begin{array}{l}\text { Average/bad vs } \\
\text { good health }\end{array}$ & $\begin{array}{l}\text { Bad/average vs } \\
\text { good health }\end{array}$ & & $\begin{array}{l}\text { Average/bad vs } \\
\text { good health }\end{array}$ & $\begin{array}{l}\text { Bad/average vs good } \\
\text { health }\end{array}$ \\
\hline $\begin{array}{l}\text { Disease index, } \\
\text { females (ind9f) }\end{array}$ & $0.031^{* * *}(0.001)$ & & & \\
\hline
\end{tabular}




\begin{tabular}{|c|c|c|c|c|}
\hline & \multicolumn{2}{|l|}{ Female } & \multicolumn{2}{|l|}{ Male } \\
\hline & $\begin{array}{l}\text { Average/bad vs } \\
\text { good health }\end{array}$ & $\begin{array}{l}\text { Bad/average vs } \\
\text { good health }\end{array}$ & $\begin{array}{l}\text { Average/bad vs } \\
\text { good health }\end{array}$ & $\begin{array}{l}\text { Bad/average vs good } \\
\text { health }\end{array}$ \\
\hline $\begin{array}{l}\text { Disease index, } \\
\text { males (ind9m) }\end{array}$ & & & $0.034 * * *(0.001)$ & \\
\hline Age & $0.053 * * *(0.002)$ & $0.047 * * *(0.002)$ & $0.052 * * *(0.001)$ & \\
\hline Single & $-0.055(0.052)$ & $0.337 * * *(0.081)$ & $0.102 *(0.057)$ & $0.628 * * *(0.093)$ \\
\hline Divorced & $-0.003(0.052)$ & $0.145^{* *}(0.064)$ & $0.123(0.085)$ & $0.392 * * *(0.109)$ \\
\hline Widowed & $0.061(0.063)$ & $0.301 * * *(0.054)$ & $0.048(0.101)$ & \\
\hline $\begin{array}{l}\text { Incomplete second- } \\
\text { ary }\end{array}$ & $0.314 * * *(0.056)$ & $0.663 * * *(0.058)$ & $0.382 * * *(0.054)$ & \\
\hline Secondary & $0.228 * * *(0.041)$ & & $0.249 * * *(0.047)$ & \\
\hline Vocational & $0.171 * * *(0.041)$ & & $0.197 * * *(0.053)$ & \\
\hline Income & $-0.073^{* * *}(0.018)$ & $-0.175^{* * *}(0.029)$ & $-0.131 * * *(0.022)$ & $-0.279 * * *(0.036)$ \\
\hline PGT & $-0.177 * *(0.081)$ & $0.263^{* * *}(0.095)$ & $-0.100(0.081)$ & \\
\hline Rural & $0.060(0.039)$ & & $-0.063(0.044)$ & \\
\hline $\begin{array}{l}\text { North and North- } \\
\text { west }\end{array}$ & $0.138(0.146)$ & $-0.436^{* *}(0.169)$ & $0.106(0.156)$ & $-0.366(0.227)$ \\
\hline $\begin{array}{l}\text { Central and Central } \\
\text { Black Eearth }\end{array}$ & $0.649 * * *(0.117)$ & $0.070(0.136)$ & $0.721 * * *(0.126)$ & $0.025(0.187)$ \\
\hline $\begin{array}{l}\text { Volga and Volga } \\
\text { Vyatski }\end{array}$ & $0.546 * * *(0.127)$ & $-0.386 * * *(0.146)$ & $0.462 * * *(0.137)$ & $-0.168(0.197)$ \\
\hline North Caucasus & $0.403 * * *(0.134)$ & $-0.246(0.156)$ & $0.420 * * *(0.144)$ & $-0.315(0.211)$ \\
\hline Urals & $0.464 * * *(0.133)$ & $-0.403^{* * *}(0.154)$ & $0.453 * * *(0.142)$ & $-0.172(0.206)$ \\
\hline Western Siberia & $0.515 * * *(0.134)$ & $-0.419 * * *(0.159)$ & $0.485 * * *(0.147)$ & $-0.333(0.217)$ \\
\hline $\begin{array}{l}\text { Eastern Siberia and } \\
\text { Far East }\end{array}$ & $0.369 * * *(0.132)$ & $-0.647 * * *(0.154)$ & $0.376^{* * *}(0.140)$ & $-0.264(0.199)$ \\
\hline GRP & $0.348 * * *(0.070)$ & & $0.542 * * *(0.085)$ & $0.267 * *(0.111)$ \\
\hline $\begin{array}{l}\text { Regional share } \\
\text { higher education } \\
\text { labour force }\end{array}$ & $-0.005(0.006)$ & $-0.041^{* * *}(0.007)$ & $-0.005(0.006)$ & $-0.022 * *(0.009)$ \\
\hline Regional Morbidity & $0.001 * * *(0.000)$ & & $0.001 * * *(0.000)$ & $0.0004 *(0.000)$ \\
\hline $\begin{array}{l}\text { Regional govern- } \\
\text { ment healthcare } \\
\text { spending }\end{array}$ & $0.112(0.135)$ & & $-0.041(0.160)$ & \\
\hline 2013 & $-0.031(0.031)$ & $0.139 * * *(0.037)$ & $0.034(0.028)$ & \\
\hline 2014 & $-0.109 * * *(0.033)$ & $0.049(0.040)$ & $0.034(0.031)$ & \\
\hline cons & $-8.652 * * *(0.912)$ & $-8.801 * * *(0.945)$ & $-9.262 * * *(1.117)$ & $-5.873 * * *(1.436)$ \\
\hline Rho & $0.605 * * *(0.009)$ & & $0.585 * * *(0.011)$ & \\
\hline $\mathrm{N}$ & 25,476 & & 18,067 & \\
\hline
\end{tabular}




\section{References}

Bago d'Uva, T., Van Doorslaer, E., Lindeboom, M., \& O’Donnell, O. (2008). Does reporting heterogeneity bias the measurement of health disparities? Health Economics, 17(3), 351-375.

Bauldry, S., Shanahan, M. J., Boardman, J. D., Miech, R. A., \& Macmillan, R. (2012). A life course model of self-rated health through adolescence and young adulthood. Social Science and Medicine, 75(7), 1311-1320.

Bos, A. M., \& Bos, A. J. (2007). The socio-economic determinants of older people's health in Brazil: the importance of marital status and income. Ageing and Society, 27, 385-405.

Cairney, J. (2000). Socio-economic status and self-rated health among older Canadians. Canadian Journal of Aging, 19(4), 456-478.

Carlson, P. (2005). Relatively poor, absolutely ill? A study of regional income inequality in Russia and its possible health consequences. Journal of Epidemiology and Community Health, 59(5), 389-394.

Cubí-Mollá, P., Jofre-Bonet, M., \& Serra-Sastre, V. (2017). Adaptation to health states: sick yet better off? Health Economics, 26(12), 1826-1843.

Doiron, D., Fiebig, D. G., Johar, M., \& Suziedelyte, A. (2015). Does self-assessed health measure health? Applied Economics, 47(2), 180-194.

Dowd, J. B., \& Zajacova, A. (2010). Does self-rated health mean the same thing across socioeconomic groups? Evidence from biomarker data. Annals of Epidemiology, 20(10), 743-749.

Economics of Transition. (2015). Special issue on Economic Change in Russia: Twenty Years of the Russian Longitudinal Monitoring Survey Guest Edited by Klara Sabirianova Peter and Guido Friebel. 23(2), 293-516.

Eibich, P. (2015). Understanding the effect of retirement on health: mechanisms and heterogeneity. Journal of Health Economics, 43, 1-12.

Etilé, F., \& Milcent, C. (2006). Income-related reporting heterogeneity in self-assessed health: evidence from France. Health Economics, 15(9), 965-981.

Eurostat statistics on self-perceived health (2014). http://ec.europa.eu/eurostat/statistics-explained/index .php/Self-perceived_health_statistics. Accessed 17 April 2019.

Frijters, P., Haisken-DeNew, J. P., \& Shields, M. A. (2005). The causal effect of income on health: evidence from German reunification. Journal of Health Economics, 24(5), 997-1017.

Gerry, C. J., \& Baidin, V. M. (2017). Sources of bias in self-assessed health. Pharmaeconomics, 10(4), 31-36.

Gerry, C. J., \& Papadopoulos, G. (2015). Sample attrition in the RLMS, 2001-10: lessons for longitudinal analysis and an application in health. Economics of Transition, 23(2), 425-468.

Gravelle, H., \& Sutton, M. (2009). Income, relative income and self-reported health in Britain 19792000. Health Economics, 18(2), 125-145.

Grossman, M. (1972). On the concept of health capital and the demand for health. Journal of Political Economy, 80(2), 223-255.

Hahn, R. A. (1999). Anthropology and the enhancement of public health practice. Anthropology in Public Health: Bridging Differences in Culture and Society, 3-24.

Health in Russia. (2017). Statistical Yearbook (p. 170). Moscow: Rosstat.

Hernández-Quevedo, C., Jones, A.M., \& Rice, N. (2004). Reporting bias and heterogeneity in selfassessed health: evidence from the British Household Panel Survey. HEDG Working Paper 05/04. York: University of York.

Hilderbrand, V., \& van Kerm, P. (2009). Income inequality and self-rated health status: evidence from the European Community Household Panel. Demography, 46(4), 805-825.

Idler, E. L. (1993). Age differences in self-assessments of health: age changes, cohort differences, or survivorship? Journal of Gerontology, 48, S289-S300.

Jürges, H. (2007). True health vs response styles: exploring cross-country differences in self-reported health. Health Economics, 16, 163-178.

Jylhä, M. (2009). What is self-rated health and why does it predict mortality? Towards a unified conceptual model. Social Science and Medicine, 69, 307-316.

Kaneva, M. A., \& Baidin, V. M. (2018). Heterogeneity in reporting self-assessed health of the Russians. Applied Econometrics, 51, 102-125.

Kaneva, M., Gerry, C., \& Baidin, V. (2018). The effect of chronic conditions and self-assessed health in Russia. Scandinavian Journal of Public Health, 46, 886-896.

Kaneva, M. A., Gerry, C. J., \& Baidin, V. M. (2019). Age differences in self-assessed health in Russia. Vestnik of Saint Petersburg University. Management, 18(4), 563-587.

Kaplan, R. M., Bush, J. W., \& Berry, C. C. (1976). Health status: types of validity and the index of wellbeing. Health services research, 11, 478-507. 
Kerkhofs, M., \& Lindeboom, M. (1995). Subjective health measures and state dependent reporting errors. Health Economics, 4, 221-235.

Kim, J. H. (2003). Assessing practical significance of the proportional odds assumption. Statistics and Probability Letters, 65(3), 233-239.

Kim, Y. (2015). The dynamics of health and its determinants among elderly in developing countries. Economics and Human Biology, 19, 1-12.

Kuchakov, R., \& Raskina, Y. (2017). Socio-economic gradient in self-reported health of the elderly in Russia and China: results of application of hierarchical ordered choice models. Finance and Business, 4, 22-46.

Lindeboom, M., \& van Doorslaer, E. (2004). Cut-point shift and index shift in self-reported health. Journal of Health Economics, 23, 1083-1099.

Lokshin, M., \& Ravallion, M. (2008). Testing for economic gradient in health using subjective data. Health Economics, 17(11), 1237-1259.

Lyytikäinen, L., \& Kemppainen, T. (2016). Regional inequalities in self-rated health in Russia: what is the role of social and economic capital? Social Science and Medicine, 161, 92-99.

Marmot, M., Allen, J., Bell, R., Bloomer, E., \& Goldblatt, P. (2012). WHO European review of social determinants of health and the health divide. Lancet, 380(9846), 1011-1029.

Monden, C. W. S., \& Uunk, W. J. G. (2013). For better and for worse: the relationship between union dissolution and self-assessed health in European panel data. European Journal of Population, 29, 103-125.

Murray, C.J., Tandon, A., Salomon, J.A., Mathers, C.D., Sadana, R. (2003) Cross-population comparability of evidence for health policy. In: C.J.L Murray \& D.B. Evans (Eds.) Health systems performance assessment: debates, methods and empiricism (pp. 705-713). Geneva: World Health Organization.

O’Doherty, M. G., French, D., Steptoe, A., \& Kee, F. (2017). Social capital, deprivation and self-rated health: does reporting heterogeneity play a role? Results from the English Longitudinal Study of Ageing. Social Science and Medicine, 179, 191-200.

Pfarr, C., Schmid, A., \& Schneider, U. (2011). Estimating ordered categorical variables using panel data: a generalized ordered probit model with autofit procedure. Journal of Economics and Econometrics, 54(1), 7-23.

Pfarr, C., Schmid, A., \& Schneider, U. (2012). Reporting heterogeneity in self-assessed health among older Europeans. Health Economics Review, 2, 21.

Regions of Russia. (2017). Statistical yearbook (p. 1402). Moscow: Rosstat.

Schneider, U., Pfarr, C., Shneider, B. S., \& Ulrich, V. (2012). I feel good! Gender differences and reporting heterogeneity in self-assessed health. European Journal of Health Economics, 13, 261-265.

Shmueli, A. (2003). Socio-economic and demographic variation in health and its measures: the issue of reporting heterogeneity. Social Science and Medicine, 57, 125-134.

Sinel'nikov, A. B. (2011). Influence of marital status on self-assessed health of population. Social Aspects of Population Health, 20(4), 9.

Russia Longitudinal Monitoring Survey (RLMS-HSE). (2019). Conducted by National Research University 'Higher School of Economics' and ZAO 'Demoscope' together with Carolina Population Center, University of North Carolina at Chapel Hill and the Institute of Sociology RAS. https://www.hse.ru/en/ rlms/. Accessed 17 April 2019.

Tandon, A., Murray, C.J., Salomon, J.A., King, G. (2003). Statistical models for enhancing cross-population comparability. Health systems performance assessment: debates, methods and empiricism. Global Programme on Evidence for Health Policy Discussion Paper No. 42 Geneva: World Health Organization.

Van Doorslaer, E., \& Gerdtham, U. G. (2003). Does inequality in self-assessed health predict inequality in survival by income? Evidence from Swedish data. Social Science and Medicine, 57(9), 1621-2162.

Watson, K., Roberts, B., Chow, C., Goryakin, Y., Rotman, D., Gasparishvili, A., et al. (2013). Micro-and meso-level influences on obesity in the former Soviet Union: a multi-level analysis. The European Journal of Public Health, 23(2), 291-298.

WHO Commission on Social Determinants of Health. (2008). Closing the gap in a generation: health equity through action on the social determinants of health: final report of the commission on social determinants of health. Geneva: WHO.

Wilkinson, R., \& Pickett, K. (2010). The spirit level: why equality is better for everyone. London: Penguin.

Publisher's Note Springer Nature remains neutral with regard to jurisdictional claims in published maps and institutional affiliations. 


\section{Authors and Affiliations}

\section{Valerii Baidin $^{1}$ (D) . Christopher J. Gerry ${ }^{2,3}$ (D) Maria Kaneva ${ }^{4,5}$ (I)}

Valerii Baidin

vbaydin@nifi.ru

Maria Kaneva

kaneva@iep.ru

1 Center for Perspective Financial Planning, Macroeconomic Analysis and Financial Statistics, Financial Institute of Research Ministry of Finance, Nastasyinsky Pereulok 3, Building 2, Office 221, Moscow 127006, Russia

2 Oxford School of Global and Area Studies (OSGA), University of Oxford, 12 Bevington Road, Oxford OX2 6LH, UK

3 Centre for Health Economics, Management, and Policy, National Research University Higher School of Economics, St Petersburg, Russian Federation

4 International Laboratory for Economics Healthcare and Its Reforms, Gaidar Institute for Economic Policy, Gazetny Pereulok 3-5, Building 1, Office 471, Moscow 125993, Russia

5 Institute of Economics and Industrial Engineering, Siberian Branch of the Russian Academy of Sciences, Novosibirsk, Russia 